\title{
EVALUATION OF NIGELLA SATIVA ON SOCKET HEALING IN RABBITS
}

\author{
Sara M. Abd Elrahman ${ }^{*} B D S$, Salwa A. Younes ${ }^{2} P h D$, Khadiga Y. Kawana² $P h D$
}

\begin{abstract}
INTRODUCTION: Tooth extraction socket healing is a complex process, which involves tissue repair and regeneration. Concurrent with bone growth into the socket, there is also well-documented resorption of the alveolar ridges. Therefore, the socket preservation concept was introduced. One of the top ranked evidence-based herbal medicines, which has been described as the "miracle herb of the century" is Nigella sativa (NS). N. sativa has been extensively studied for its biological activities and therapeutic potential and shown to possess wide spectrum of activities.
\end{abstract}

OBJECTIVES: To evaluate the biological effect of Nigella sativa on socket healing in rabbits.

MATERIALS AND METHODS: Twelve healthy rabbits were used in this study, lower first premolars (right and left) were extracted. All right sockets were left for normal healing as a control group, while the left sockets are considered as the study group and they were treated with Nigella Sativa. All sockets were sutured. Rabbits were sacrificed after two weeks. Their mandibles were dissected out to be processed for histological examination under the light microscope.

RESULTS: In the control group, the histological examination of the socket revealed randomly arranged thin bony spicules lined by flattened layer of osteoblast cells on its surface, enclosing fibrous bone marrow with limited vascularity. Osteocytes were of moderate size and density. In the Nigella sativa treated group sockets exhibited more active bone formation, thick trabeculae with highly vascular bone marrow and large numerous osteocytes. Certain areas show replacement of woven bone with mature bone where bone remodeling takes place.

CONCLUSIONS: Use of Nigella sativa after extraction in the healing sockets could enhance bone formation and accelerate the process of socket healing

KEYWORDS: Nigella sativa, socket healing, rabbit, bone formation

1- Demonstrator of Oral Biology,, Faculty of Dentistry, Alexandria University, Egypt.

2- Professor of Oral Biology, Department of Oral Biology, Faculty of Dentistry, Alexandria University, Egypt.

*Corresponding author:

E-mail: rosysaso222@gmail.com

\section{INTRODUCTION}

Dental extraction (also referred to exodontia) is the removal of teeth from their sockets in the alveolar bone. It is one of the most widely performed dental procedures. It is carried out for many reasons but most commonly to remove teeth which have become unrestorable through tooth decay, periodontal disease or dental trauma, especially when they are associated with toothache. Also in orthodontics if the teeth are crowded, sound teeth may be extracted (often bicuspids) to create space so the rest of the teeth can be straightened (1).

Tooth extraction socket healing is a complex process, which involves tissue repair and regeneration. It encompasses chemotaxis of proper cells into the wound, transformation of undifferentiated mesenchymal cells to osteoprogenitor cells, proliferation of committed bone forming cells, extra cellular matrix synthesis, mineralization of osteoid, maturation, and remodeling of bones (2).

The extraction of a tooth initiates a series of reparative processes involving both hard tissue (i.e. alveolar bone) and soft tissues (periodontal ligament, gingiva). The biological events occurring during the healing of an extraction socket and their chronological sequence have been studied in different animal models which helped to characterize the tissues involved in the healing process of extraction sockets. According to the existing literature, a gross classification of these tissues can be the following: blood clot (BC), consisting of erythrocytes and leukocytes embedded in a fibrin network (3); granulation tissue (GT), rich in newly formed vascular structures, inflammatory cells as well as erythrocytes (4); provisional matrix (PM), presenting densely packed mesenchymal cells, collagen fibers and vessels but no or only scattered inflammatory cells (5); woven bone (WB), consisting of fingerlike projections of immature bone embedded in a primary spongiosa (6); lamellar bone and marrow (LB/BM), i.e. lamellae of mature, mineralized bone harboring secondary osteons surrounded by marrow spaces rich in vessels, adipocytes, mesenchymal cells and inflammatory cells (7).

Post-extraction healing of both the hard and soft tissues proceeds uneventfully. However, even with uneventful healing, the alveolar defect that results as a consequence of tooth removal, will only become partially restored. Concurrent with bone growth into the socket, there is also well documented, resorption of the alveolar ridges. The greatest amount of bone loss is in the horizontal dimension and occurs mainly on the facial aspect of the ridge. There is also loss of vertical ridge height, which has been described to be most pronounced on the buccal aspect (8).

Bone resorption after tooth extraction can make dental implant treatment difficult and impairs the long-term functional stability of the implant and the esthetic results of prosthodontic treatment. Therefore, the socket preservation concept was introduced. Socket preservation or alveolar ridge preservation (ARP) is a procedure to reduce bone loss after tooth extraction to preserve the dental alveolus (tooth socket) in the alveolar bone. It is performed immediately after tooth extraction (9). It has been found that ridge preservation procedures following tooth extraction result in greater orofacial dimension of bone when compared with 
cases where no ridge preservation procedures are completed (10).

A number of biomaterials for socket grafting have been reported, including autogenous, Allogeneic, xenogeneic, and alloplastic, bone grafts and other materials such as platelet-rich plasma, platelet-rich fibrin, bone morphogenetic protein, Emdogain, and cell therapy (11).

Today's world is increasingly seeking ways to replace the synthetic drugs with the therapeutic power of natural products. Interest in medicinal plants has burgeoned due to increased efficiency of new plant-derived drugs and the growing interest in natural products. Because of the concerns about the side effects of conventional medicine, the use of natural products as an alternative to conventional treatment in healing and treatment of various diseases has been on the rise in the last few decades (12).

One of the top ranked evidence-based herbal medicines, which has been described as the "miracle herb of the century" is Nigella sativa (NS). It has been extensively studied for its biological activities and therapeutic potential and shown to possess wide spectrum of activities such as diuretic, antihypertensive, antidiabetic, anticancer and immunomodulatory, antimicrobial, analgesics and antiinflammatory, bronchodilator, gastroprotective, hepatoprotective, renal protective and antioxidant properties $(13,14)$.

The chemical composition of Nigella sativa contains volatile and non-volatile oils in addition to many other active ingredients including proteins, alkaloids, coumarines, saponins, minerals, carbohydrates, phenolic compounds, steroidal compounds, and other ingredients (15).

To the best of our knowledge, the literature contains few data on the effect of Nigella sativa on the process of socket healing after tooth extraction and this is why this study was carried out.

\section{MATERIALS AND METHODS}

\section{Experimental animals}

This study was conducted on 12 healthy rabbits, weighing (2.125-2.250 kg), aged 14-16 weeks. The animals were obtained from the Institute of Medical Research, Alexandria University. The rabbits were kept at a constant humidity and temperature of about $23^{\circ} \mathrm{C}$ and supplied a regular diet throughout the whole experimental period ( 2 weeks). The study was conducted after the approval of the Research Ethics Committee, Faculty of Dentistry Alexandria University.

Rabbits have 28 teeth, the dental formula of the adult rabbit is: 2 (I 2/1, C 0/0/, P 3/2, M 3/3).

\section{Experimental procedure}

The rabbits were subjected to extract their lower first premolars (right and left) under general anesthesia.

\section{The animals were grouped into}

The control group: in which all the right first premolar sockets were left for normal healing process without removal of blood clot after extraction process.

The study group: left first premolar sockets were treated with Nigella sativa oil by using a piece of cotton impregnated in oil then inserted inside the socket and waiting for five minutes then was removed.

All sockets were sutured. The animals were sacrificed after two weeks and the mandibles were dissected out, the two halves were separated for grouping and to be prepared for histological examination.

\section{Histological procedures}

The two halves of the mandible were fixed immediately in $10 \%$ neutral buffered formalin solution for 10 days, washed, decalcified in $8 \%$ trichloroacetic acid, dehydrated by passing through a series of ascending percentages of ethyl alcohol, cleared with xylene, and embedded in paraffin wax blocks. Sections were cut at a thickness of $5 \mu \mathrm{m}$ and stained with Hematoxylin and Eosin and Trichrome stains then examined by light microscope (16).

\section{Histomorphometric analysis}

Computer assisted histomorphometry was performed in order to measure the percentage of the new formed bone surface area in the two groups. From each group block three sections were obtained from the standardized depths. The bone surface area was calculated using software "Image J 1.46”. Measurements were obtained from each slide then the mean values were calculated.

\section{Statistical analysis}

The collected data of the percentage of bone surface area were statistically analyzed by using paired t test to reveal the difference between the study and control groups by means of IBM SPSS software (Armonk, New York: IBM Corporation).

\section{RESULTS}

\section{Histological results}

\section{Control group}

The histological examination of the socket revealed fibrous tissue and newly formed bone. (Fig.1)

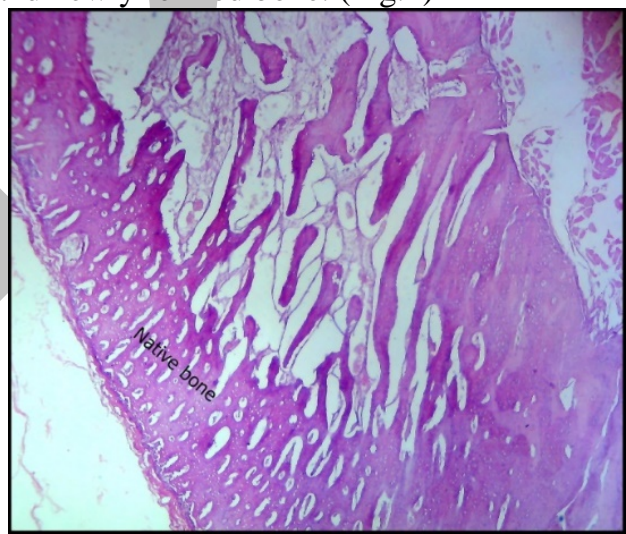

Figure (1): (LM), (control group, 2 weeks) showing the socket filled with fibrous tissue and thin bone spicules, H\&E stain X40

Randomly arranged thin bony spicules could be seen at the base of the socket lined by a flattened layer of osteoblast cells on its surface, enclosing fibrous bone marrow with limited vascularity. Osteocytes were of moderate size and density (Fig 2,3).

\section{Study group (sockets treated with NS oil)}

In this group, sockets revealed more active bone formation, thick trabeculae with highly vascular bone marrow and large numerous osteocytes. (Fig.4,6)

Certain areas showed replacement of woven bone with mature bone. Incremental lines could be clearly seen. (Fig.5) 


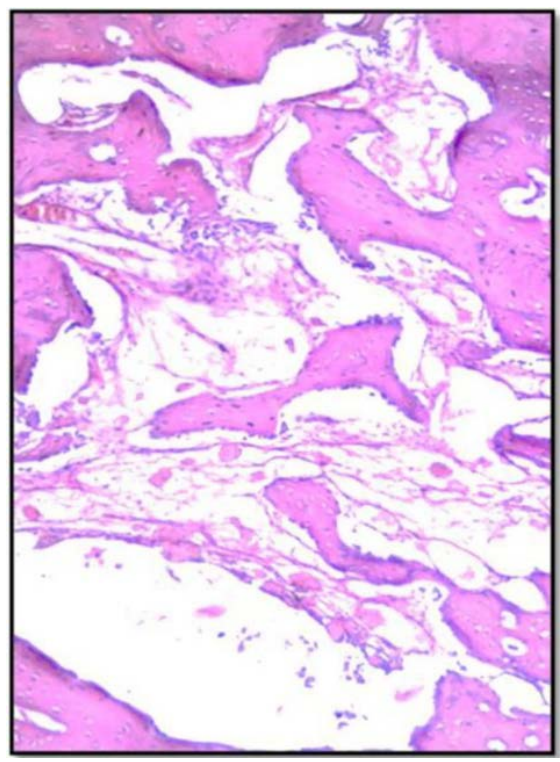

Figure (2): (LM), (control group, 2 weeks) showing thin newly formed woven bone surrounded by fibrous tissue, $\mathrm{H} \& \mathrm{E}$ stain $\mathrm{X}$ 100.

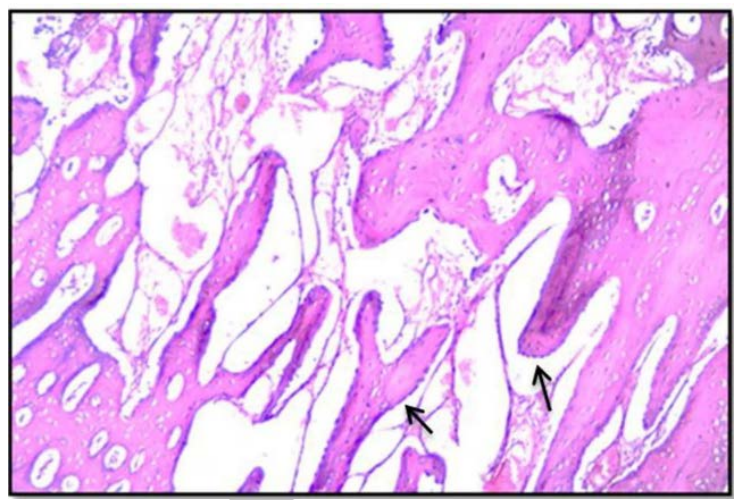

Figure (3): (LM), (control group, 2 weeks), showing randomly oriented bony spicules lined by flat layer of osteoblast cells (arrows), Note limited blood supply and numerous osteocytes, H\&E stain X 100.

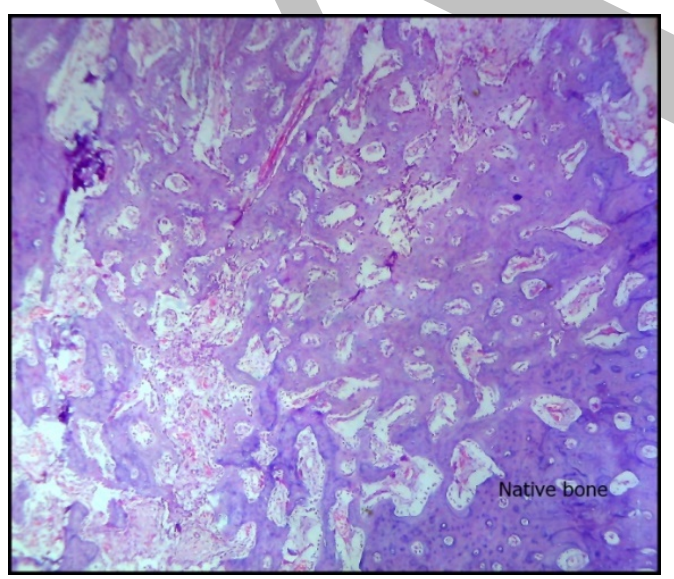

Figure (4): (LM), (study group, 2 weeks) showing a dense mass of newly formed bone at the lateral walls of the socket, $H \& E$ stain X40

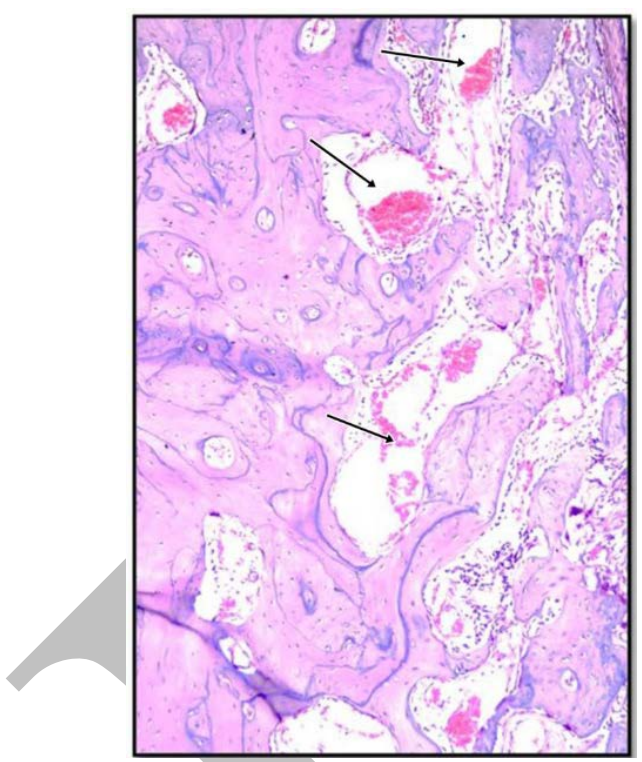

Figure (5): (LM), (study group, 2 weeks) showing newly formed bone undergo remodeling enclosing bone marrow with dilated blood vessels (arrows), Note well demarcated incremental lines, H\&E stainX 100

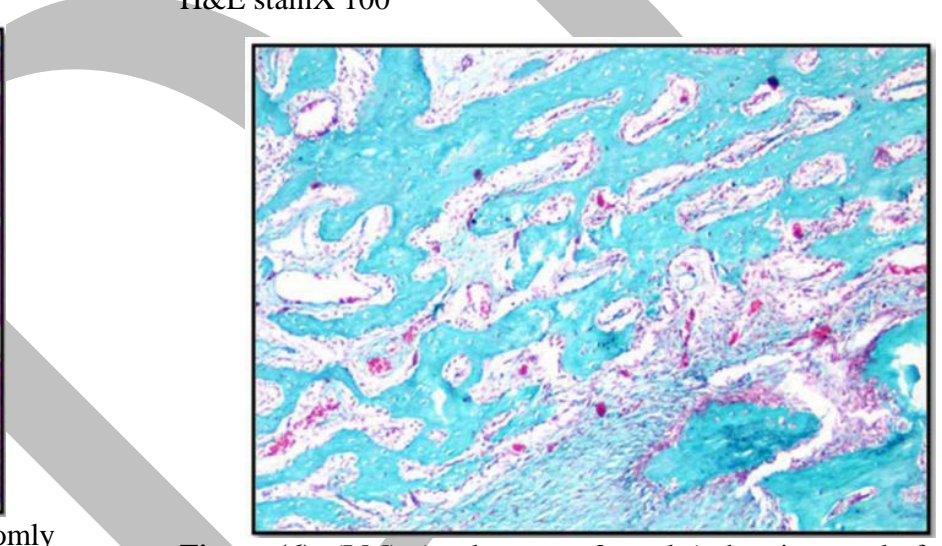

Figure (6): (LM), (study group, 2 weeks) showing newly formed bone with large aggregate of osteocytes, enclosing rich blood supply. Trichrome stain X 100.

\section{Histomorphometric Results}

Table (1) shows comparison between the two groups included in the study (control, Nigella sativa oil group) regarding the percentage of the newly formed bone surface area (\%), where the mean values $21.54 \pm 2.28$ and 44.11 \pm 2.58 respectively.

It was noted that the study (Nigella sativa oil) group exhibited higher percentage of new bone formation in comparison to control group. Moreover, the difference between the two groups was statistically significant $\mathrm{p}<$ 0.001 .

Table (1): Comparison between the two studied groups according to percent of newly formed bone

\begin{tabular}{|l|c|c|c|c||}
\hline $\begin{array}{c}\text { Percent of } \\
\text { newly } \\
\text { formed bone }\end{array}$ & Control & Study & t & p \\
\hline Min. - Max. & $17.50-24.17$ & $39.53-48.20$ & & \\
Mean \pm SD. & $21.54 \pm 2.28$ & $44.11 \pm 2.58$ & $17.345^{*}$ & $<0.001^{*}$ \\
Median & 21.71 & 44.02 & & \\
\hline
\end{tabular}

\section{t: Student t-test}

$\mathrm{p}: \mathrm{p}$ value for comparing between the two groups

*: Statistically significant at $\mathrm{p} \leq 0.05$

Study group: (Nigella sativa oil) 


\section{DISCUSSION}

Tooth extraction socket healing is a complex process, which involves tissue repair and regeneration. It encompasses chemotaxis of proper cells into the wound, transformation of undifferentiated mesenchymal cells to osteoprogenitor cells, proliferation of committed bone forming cells, extra cellular matrix synthesis, mineralization of osteoid, maturation, and remodeling of bones (2).

Extensive studies have been carried out to control alveolar bone resorption and accelerate new bone formation after tooth extraction. One of the top ranked herbal medicines, which has been described as the "miracle herb of the century is Nigella sativa (NS). N. sativa has been extensively studied for its biological activities and therapeutic potential and shown to possess wide spectrum of activities (17). The current study aimed to evaluate using Nigella Sativa after tooth extraction and its effect on the process of socket healing.

In the present study, two weeks after extraction, the histological examination of the sockets of the control group revealed newly formed bony spicules and dense fibrous tissue with limited blood supply. These findings are supported by Kuboki et al. (18) as they studied the time dependent changes in the socket after tooth extraction in rabbits. The formation of new bone in the socket occurs when the granulation tissue that was occupying the socket in earlier stage becomes diminished and replaced by fibrous tissue which is penetrated by blood vessels and bone forming cells that lay down newly formed woven bone (3).

The formation of new bone during the process of socket healing may be attributed to the activity of the growth factors. They have important functions both for the initiation and maintenance of differentiation and proliferation of the osteoprogenitor cells and osteoblasts which contribute to the formation of new bone. In the early phases of healing, TGF-B and PDGF released from platelets from the blood clot, initiate differentiation of osteoprogenitor cells towards an osteoblastic lineage. Growth factors released from the traumatized bone ends can contribute to continued stimulation of osteoblastic activity as well. The initiation of healing by growth factor released from platelets and bone tissue stimulates specific expression and synthesis of growth factors by the osteoblasts participating in the healing process (19). Very early, after 2 days, BMP is expressed by periosteal osteoblasts during the healing process. This synthesis could contribute to the continuous osteoblastic differentiation of mesenchymal stem cells. Later (after 7-12 days), other growth factors like TGF-B, FGF and PDGF are synthesized by osteoblasts in order to maintain a high proliferative and metabolic level of the osteoblasts that are involved in the healing process (2022).

On the other hand, the sockets of the study group treated with Nigella sativa oil show more active bone formation with thicker bony trabeculae and highly vascular bone marrow, these results are in agreement with E'atelaf (23). As she studied the effect of Nigella sativa oil extract as a topical treatment on bone defect healing in rabbits histologically and radiographically, the study group treated with NS oil showed enhancement in bone healing regarding deposition and angiogenesis.

In a recent study the histopathological effect of thymoquinone (TQ) (active ingredient of Nigella Sativa) administration on healing of bone defects in rat tibia was evaluated (24). It was reported that TQ-administered groups showed an increase in bone formation and capillary intensity in the defect area compared to the control group, they concluded that the systemic administration of TQ accelerated new bone formation in a rat model and could be advocated as an adjunct to expedite bone healing.

Regarding the vascularity, In the present study the histological results of the control sockets showed marrow spaces with limited blood supply while the Nigella treated socket revealed dilated blood vessels during the formation of regenerated bone which is thought to indicate active bone formation. These findings are in agreement with Akhtar et al (2012) (25) who proved that Nigella sativa has beneficial role for improving the blood supply.

Bone regeneration is dependent upon angiogenesis which provides precursor cells and nutrients to the area of the bony defect (extraction socket) $(26,27)$.

Also, Nigella sativa is believed to have angiogenic effects, $\mathrm{Al}$ Asoom (28) studied the effect of long term administration of Nigella sativa on coronary angiogenesis in Wistar rats using immunohistological techniques to detect the VEGF (vascular endothelial growth factor) and vWF (von Willibrand factor). VEGF is a growth factor that induces the sprouting of the capillaries (29). It does so by dissolving the basement membrane of the existing capillaries, and then stimulating the proliferation and migration of endothelial cells (30), while vWF is a glycoprotein that is synthesized in the endothelial cells, vWF plays a role in the regulation of angiogenesis, limits the release of angiogenic factors, such as VEGF (31). Inhibition of the release and synthesis of vWF by interfering with its genetic expression in mice leads to enhanced angiogenesis, increased VEGF receptor-2 dependent proliferation and migration of endothelial cells (32). In this study, VEGF was significantly higher in the NS group, with significantly lower vWF expression level than the control group indicating that NS administration is a potential factor for the induction of capillary growth.

Therefore, N. sativa is believed to provide important factors which contributed in enhancement the healing process of the bone defect.

\section{CONCLUSION}

From the previous finding, it could be concluded that administration of Nigella Sativa after teeth extraction may enhance bone formation and accelerate the process of socket healing.

\section{CONFLICT OF INTEREST}

The authors declare that they have no conflicts of interest.

\section{REFERENCES}

1-Hupp JR, Ellis E, Tucker MR. Contemporary oral and maxillofacial surgery. 5th ed. St. Louis, Mo.: Mosby Elsevier; 2008.

2-Lalani Z, Wong M, Brey EM, Mikos AG, Duke P. Spatial and temporal localization of transforming growth factor-b1, bone morphogenetic protein-2, and platelet-derived growth factor-A in healing tooth extraction sockets in a rabbit model. J Oral Maxillofac Surg.2003;61:1061-72.

3-Cardaropoli G, Araújo M, Lindhe J. Dynamics of bone tissue formation in tooth extraction sites. An experimental study in dogs. J Clin Periodontol.2003;30:809-18.

4-Guo S, DiPietro LA. Factors affecting wound healing. J Dent Res.2010;89:219-29. 
5-Velnar T, Bailey T, Smrkolj V. The wound healing process: an overview of the cellular and molecular mechanisms. J Int Med Res.2009;37:1528-42.

6-Chen ST, Wilson Jr TG, Hammerle C. Immediate or early placement of implants following tooth extraction: review of biologic basics, clinical procedures, and outcomes. Int J Oral Maxillofac Implants.2004;19:12-25.

7-Iizuka T, Miller SC, Marks SC. Alveolar bone remodeling after tooth extraction in normal and osteoporotic (ia) rats. J Oral Pathol Med.1992;21:150-5.

8-Van der Weijden F, Dell'Acqua F, Slot DE. Alveolar bone dimensional changes of postextraction sockets in humans: a systematic review. J Clin Periodontol.2009;36:1048-58.

9-Peck MT1, Marnewick J, Stephen L. Alveolar Ridge Preservation Using Leukocyte and Platelet-Rich Fibrin: A Report of a Case. Case Rep Dent.2011:1-5.

10-Chen ST. Clinical and Esthetic Outcomes of Implants Placed in Postextraction Sites. Int J Oral Maxillofac Implants.2009;24:186-2.

11-Jamjoom A, Cohen RE. Grafts for Ridge Preservation. J Funct Biomater.2015;6:833-48.

12-Sogut B, Celik I, Tuluce Y. The effect of diet supplemented with the Black cumin upon Immune potential and antioxidant marker enzymes and lipid peroxidation in broiler chicks. J Anim Vet Adv.2008;7:1196-9.

13-Ahmad I, Tripathi J, Sharma M, Karchulli MS, Umer L. Nigella sativa - a medicinal herb with immense therapeutic potential (a systematic review). Int J Biol Pharma Res. 2014;5:755-62.

14-Ahmad A, Husain A, Mujeeb M, Khan SA, Najmi AK, Siddique NA, et al. A review on therapeutic potential of Nigella sativa: A miracle herb. Asian Pac J Trop Biomed. 2013;3:337-52

15-El-Tahir KH, Bakeet D. The Black seed Nigella Sativa: Aplea for urgent clinical evaluation of its volatile oil. JTU Med Sci.2006;1:1-19.

16-Orban BJ, Bhaskar SN. Oral histology and embryology.11th ed. Saint Louis: Mosby;1991.

17-Goreja WG. Black seed: nature's miracle remedy. New York, NY: Amazing Herbs Press; 2003.

18-Kuboki Y, Hashimoto F, Ishibashi K. Time dependent changes of collagen cross links in the socket after tooth extraction in rabbits. J Dent Res.1988;67:944-8.

19-Centrella M, McCarthy TL, Canalis E. Effects of transforming growth factors on bone cells. Con Tiss Res.1989;20:267-75.

20-Joyce ME, Jingushi S, Bolander ME. Transforming growth factor-8 in the regulation of fracture repair. Orthop Clin North Am.1992;21:199-209

21-Nakase T, Nomura S, Yoshikawa H, Hashimoto J, Hirota S, Kitamura Y, et al. Transient and localized expression of bone morphogenetic protein 4 messenger RNA during fracture healing. J Bone Miner Res.1994;9:651-9.

22-Sandberg MM. Matrix in cartilage and bone development: current views on the function and regulation of major organic components. Ann Med.1991;23:207-17.

23-Eatelaf A. The percutaneous effect of black seed (Nigella Sativa) oil as external topical treatment on bone healing in rabbits. QJVMS.2014;13:146-54.

24-Arslan AH, Tomruk CÖ, Meydanlı EG, Özdemir İ, Duygu Çapar G, Kütan E, et al. Histopathological evaluation of the effect of systemic thymoquinone administration on healing of bone defects in rat tibia. Biotechnol Biotec Eq.2017;31:175-81.
25-Akhtar M, Maikiyo AM, Khanam R, Mujeeb M, Aqil M, Najmi AK. Ameliorating effects of two extracts of Nigella sativa in middle cerebral artery occluded rat. J Pharm Bioallied Sci.2012;4:70-5.

26-Gerber HP, Vu TH, Ryan AM, Kowalski J, Werb Z, Ferrara N.VEGF couples hypertrophic cartilage remodeling, ossification and angiogenesis during endochondral bone formation. Nat Med.1999;5:623-8.

27-Glowacki J. Angiogenesis in fracture repair. Clin Orthop Relat Res.1998;355:S82-9.

28-Al Asoom LI. Coronary angiogenic effect of long-term administration of Nigella sativa. BMC Complement Altern Med. 2017;17:308.

29-Zheng W, Seftor EA, Meininger CJ, Hendrix MJ, Tomanek RJ. Mechanisms of coronary angiogenesis in response to stretch: role of VEGF and TGF-beta. Am J Physiol Heart Circ Physiol.2001;280:H909-17.

30-Kolmakova A, Rajesh M, Zang D, Pili R, Chatterjee S. VEGF recruits lactosylceramide to induce endothelial cell adhesion molecule expression and angiogenesis in vitro and in vivo. Glycoconj J.2009;26:547-58.

31-Randi AM, Laffan MA, Starke RD. Von Willebrand factor, angiodysplasia and angiogenesis. Mediterr J Hematol Infect Dis.2013;5:e2013060.

32-Starke RD, Ferraro F, Paschalaki KE, Dryden NH, McKinnon TA, Sutton RE, et al. Endothelial von Willebrand factor regulates angiogenesis. 